\title{
Layer-by-layer assembly of functionalized reduced graphene oxide for direct electrochemistry and glucose detection
}

\author{
Daniela Branco Tavares Mascagni ${ }^{\mathrm{a}}$, Celina Massumi Miyazaki ${ }^{\mathrm{b}}$, Nilson Cristino da Cruz ${ }^{\mathrm{a}}$, \\ Marli Leite de Moraes ${ }^{\mathrm{c}}$, Antonio Riul Jr ${ }^{\mathrm{d}}$, Marystela Ferreira ${ }^{\mathrm{b}, *}$ \\ a São Paulo State University - UNESP, Sorocaba, São Paulo, Brazil \\ b Federal University of São Carlos, UFSCar, Campus Sorocaba, SP, Brazil \\ ' Federal University of São Paulo, Unifesp, Campus São José dos Campos, SP, Brazil \\ d University of Campinas - Unicamp, Campinas, São Paulo, Brazil
}

\section{A R T I C L E I N F O}

\section{Article history:}

Received 5 April 2016

Received in revised form 16 May 2016

Accepted 1 June 2016

Available online 2 June 2016

\section{Keywords:}

Glucose oxidase biosensor

Direct electron transfer

Self-assembled films

Functionalized rGO

\begin{abstract}
A B S T R A C T
We report an electrochemical glucose biosensor made with layer-by-layer ( $\mathrm{LbL}$ ) films of functionalized reduced graphene oxide ( $\mathrm{rGO}$ ) and glucose oxidase ( $\mathrm{GOx}$ ). The LbL assembly using positively and negatively charged $\mathrm{rGO}$ multilayers represents a simple approach to develop enzymatic biosensors. The electron transport properties of graphene were combined with the specificity provided by the enzyme. rGO was obtained and functionalized using chemical methods, being positively charged with poly(diallyldimethylammonium chloride) to form GPDDA, and negatively charged with poly(styrene sulfonate) to form GPSS. Stable aqueous dispersions of GPDDA and GPSS are easily obtained, enabling the growth of LbL films on various solid supports. The use of graphene in the immobilization of GOx promoted Direct Electron Transfer, which was evaluated by Cyclic Voltammetry. Amperometric measurements indicated a detection limit of $13.4 \mu \mathrm{mol} \cdot \mathrm{L}^{-1}$ and sensitivity of $2.47 \mu \mathrm{A} \cdot \mathrm{cm}^{-2} \cdot \mathrm{mmol}^{-1} \cdot \mathrm{L}$ for glucose with the $(G P D D A / G P S S)_{1} /(G P D D A / G O x)_{2}$ architecture, whose thickness was $19.80 \pm 0.28 \mathrm{~nm}$, as determined by Surface Plasmon Resonance (SPR). The sensor may be useful for clinical analysis since glucose could be detected even in the presence of typical interfering agents and in real samples of a lactose-free milk and an electrolyte solution to prevent dehydration.
\end{abstract}

(c) 2016 Elsevier B.V. All rights reserved.

\section{Introduction}

The incidence of diabetes will double by 2030, according to the World Health Organization [1], thus requiring massive investment in prevention research, including development of sensitive devices capable of detecting glucose from several intake sources such as food and medicines. Efforts have been made in this direction, with enzymes being used to provide high specificity to sensors [2]. Since the first enzyme biosensor for detecting glucose by Clark [3], considerable advances have been achieved in methodologies for immobilizing biomolecules. The key to successful enzyme immobilization is the preservation of its biocatalytic activity in the recognition of a specific element, which is provided by electron transfer reactions from the redox process involving the analyte. Therefore, the structure of the biomolecule should be preserved after the immobilization process.

* Corresponding author at: Rod. João Leme dos Santos, km 110 - CEP, 18052-780 Sorocaba, SP, Brazil.

E-mail address: marystela@ufscar.br (M. Ferreira).
The layer-by-layer ( $\mathrm{LbL}$ ) technique is a relatively simple, versatile, robust and low-cost method for fabricating ultrathin films [4], which can be used to functionalize surfaces for several applications, including sensing and biosensing. It has been shown to be effective with several types of materials such as enzymes [5], dendrimers [6], polypeptides [7], nucleic acids and DNA [8], proteins [9], virus [10], conducting polymers [11], inorganic materials [12], nanoparticles [13], nanotubes [14] and nanowires and nanosheets [15]. It is widely used for immobilizing biomolecules [16-18] as the electrochemical activity is preserved due to water entrapment in the LbL film structure [19], minimizing protein denaturation for long time periods [20].

While devising a biosensor made with LbL films, one has to consider not only the choice of a matrix material capable of preserving the activity of biomolecules but also the need to have efficient charge transport. In this context, graphene is unique in that a single sheet free of defects exhibits high electrical conductivity [21], with electrons moving at nearly the speed of light $\left(\sim 10^{6} \mathrm{~m} / \mathrm{s}\right)$ [22]. With such properties, graphene has been used in electrochemical sensors, for detecting reduction of bromate [23], single nucleotide polymorphisms of DNA [24], leukemia [25, 


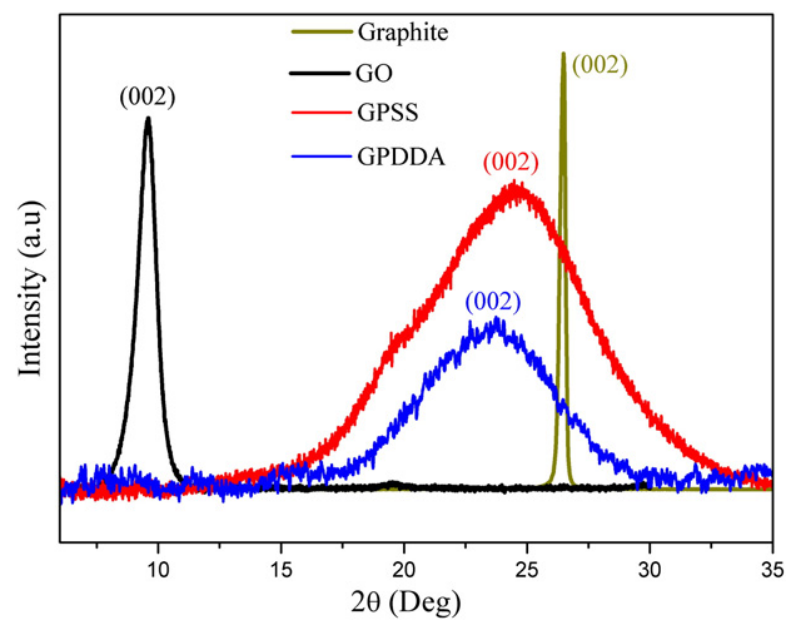

Fig. 1. XRD patterns of graphite, GO, GPDDA and GPSS powder, including the crystalline orientation of the XRD peaks.

26] and dopamine [15]. However, graphene is highly hydrophobic and forms clusters when dispersed in water [27]. To increase applicability in LbL assemblies, graphene nanosheets are normally functionalized with stabilizers for aqueous dispersions. LbL films fabricated with functionalized rGO, for instance, feature tunable film thickness [28], with electrons from protein active sites permeating the protective shell for the LbL film, thereby improving the analytical performance of a biosensor [29]. The use of graphene in the immobilization of glucose oxidase (GOx) has promoted Direct Electron Transfer (DET) [30-34], which is advantageous for sensing for several reasons, including reagent-less detection, low operation potential and high selectivity [29].

In this work, graphene nanosheets were chemically synthesized from graphite and stabilized in positively charged PDDA and negatively charged PSS, thus producing, respectively, rGO stabilized in PDDA (GPDDA) and rGO stabilized in PSS (GPSS). Aqueous stable dispersions of the functionalized rGO nanoplatelets were used for producing $\mathrm{LbL}$ films alternated with GOx. We have chosen the LbL technique owing to its suitability to immobilize enzymes with their structure and biocatalytic activity preserved. The architecture (GPDDA/GPSS) ${ }_{1} /($ GPDDA/ $\mathrm{GOx})_{2}$ was self-assembled onto an ITO substrate and successfully tested for the electrochemical determination of glucose. Amperometry was used for glucose detection and different interferents were tested.

\section{Materials and methods}

\subsection{Materials}

Graphite powder with $98 \%$ purity, $95 \% \mathrm{H}_{2} \mathrm{SO}_{4}, \mathrm{Na}_{2} \mathrm{HPO}_{4}, 99 \%$ $\mathrm{KMnO}_{4}, 99 \% \mathrm{~K}_{2} \mathrm{~S}_{2} \mathrm{O}_{3}, \mathrm{P}_{2} \mathrm{O}_{5}, 30 \% \mathrm{H}_{2} \mathrm{O}_{2}$, hydrazine sulfate $\left(\mathrm{H}_{6} \mathrm{~N}_{2} \mathrm{O}_{4} \mathrm{~S}\right)$ and $\mathrm{NaH}_{2} \mathrm{PO}_{4}$ were purchased from Synth. Glucose Oxidase (GOx) from Aspergillus niger $\left(138,800\right.$ units $\left.\cdot \mathrm{g}^{-1}\right), 99.5 \% \mathrm{D}-(+)$-glucose, poly(styrene sulfonic acid) sodium salt (PSS; $\mathrm{Mw}=70,000$ ) and poly (diallyldimethylammonium chloride) (PDDA; 20 wt.\% in $\mathrm{H}_{2} \mathrm{O}$ ) were purchased from Sigma Aldrich. All reagents were obtained as analytical grade and used without further purification.

\subsubsection{Instruments}

X-ray diffraction (XRD) studies were performed with a XPERT-PRO MPD (PANalytical) diffractometer using $\mathrm{Cu} K \alpha$ radiation $(\lambda=$ $1.544 \AA$ ) . UV-Vis spectroscopy was carried out using Genesys 6 UV-visible spectrophotometer (Thermo Fischer). To analyze the LbL film growth, the SPR Navi 200 Surface Plasmon Resonance (SPR) analyzer
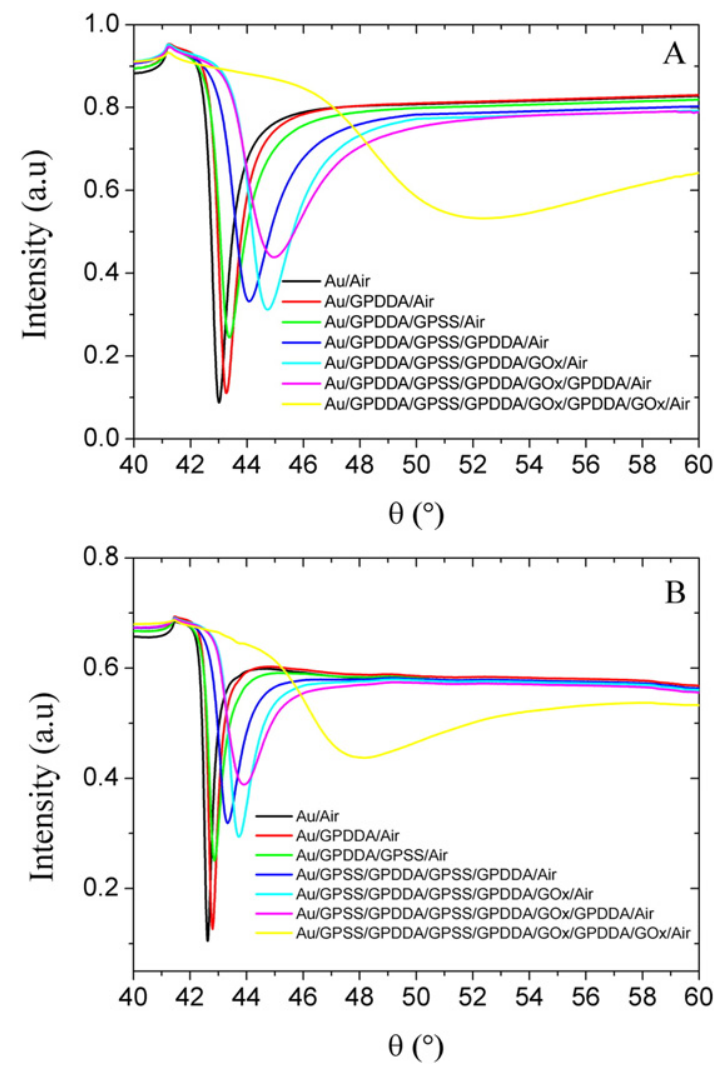

Fig. 2. SPR angular spectra for gold sensor during deposition of (a) (GPDDA/GPSS) $1 /$ $(\mathrm{GPDDA} / \mathrm{GOx})_{2}$ film excited by $\lambda=670 \mathrm{~nm}$ laser and (b) $\lambda=785 \mathrm{~nm}$ laser.

(BioNavis, Finland) was used, with a $p$-polarized laser light beam at two wavelengths, viz. $\lambda=670 \mathrm{~nm}$ and $\lambda=785 \mathrm{~nm}$. Previously cleaned gold covered glass slides (BioNavis, Finland) were used as substrates for the SPR experiments. Fourier Transform Infrared (FTIR) spectroscopy was carried out using a Nexus 470 (Thermo Nicolet). The films were assembled onto silicon substrates and the pure components were compressed in $\mathrm{KBr}$ pellets. Circular dichroism (CD) spectroscopy was carried out on a J-815 spectrometer (JascoInc) with a bandwidth of $1 \mathrm{~nm}$, a response time of $0.5 \mathrm{~s}$ and a scanning rate of $100 \mathrm{~nm} \cdot \mathrm{min}^{-1}$. The GOx solution was analyzed using a quartz cell of $1 \mathrm{~mm}$ optical path and the films were analyzed on quartz substrates, with the optical path given by the film thickness. Chronoamperometry was performed on a potentiostat/galvanostat (Autolab PGSTAT 30 - Echochemie). A conventional three-electrode system was used with a working electrode of (PDDA/GPSS $)_{1} /(\text { GPDDA/GOx })_{2}$ film onto ITO, a platinum plate as counter electrode, and a saturated calomel electrode (SCE) as the reference electrode. All electrochemical measurements were acquired in $10 \mathrm{mmol} \cdot \mathrm{L}^{-1}$ and phosphate buffer $\mathrm{pH}$ 6.3.

\subsubsection{Synthesis of GPSS and GPDDA}

Graphite was pre-oxidized as reported by Kovtyukhova [35]. $15 \mathrm{~mL}$ of $\mathrm{H}_{2} \mathrm{SO}_{4}$ were mixed with $5 \mathrm{~g}$ of $\mathrm{K}_{2} \mathrm{~S}_{2} \mathrm{O}_{8}$ and $5 \mathrm{~g} \mathrm{P} \mathrm{P}_{2}$ kept at $80{ }^{\circ} \mathrm{C}$, then $10 \mathrm{~g}$ of graphite powder were added to the mixture, which was cooled to room temperature, carefully diluted and filtered. Graphite oxide was prepared from graphite powder using a modified Hummers method [36]. Briefly, $10 \mathrm{~g}$ of pre-oxidized graphite were mixed in $230 \mathrm{~mL}$ concentrated $\mathrm{H}_{2} \mathrm{SO}_{4}$ kept in an ice bath at $0{ }^{\circ} \mathrm{C}$ and $30 \mathrm{~g}$ of $\mathrm{KMnO}_{4}$ were added gradually to the mixture. This mixture was stirred for $2 \mathrm{~h}$ at $35^{\circ} \mathrm{C}$ and diluted gradually with $460 \mathrm{~mL}$ of ultrapure water. After $15 \mathrm{~min}$, the mixture was diluted with $1.4 \mathrm{~L}$ of ultrapure water and treated with $30 \mathrm{~mL} 30 \% \mathrm{H}_{2} \mathrm{O}_{2}$ (the color of the mixture turned to 

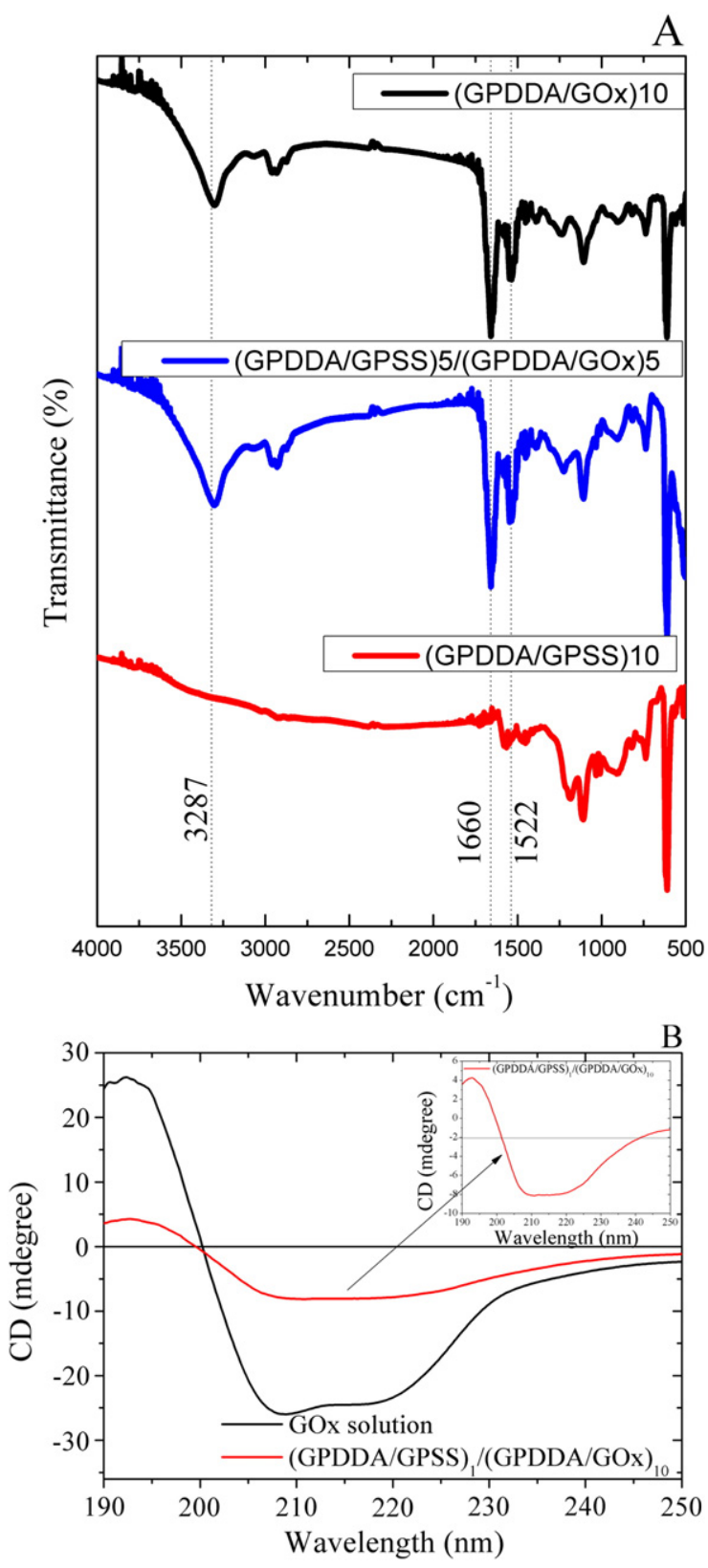

Fig. 3. (a) FTIR spectra of the (GPDDA/GOx $)_{10}$, (GPDDA/GPSS $)_{5} /(\mathrm{GPDDA} / \mathrm{GOx})_{5}$ and (GPDDA/GPSS) ${ }_{10}$ film on silicon substrate. (b) CD spectra of free GOx in solution (black curve) and (GPDDA/GPSS $)_{1} /(\text { GPDDA/GOx })_{10}$ film (red curve). Inset: the amplified CD spectrum of (GPDDA/GPSS $)_{1} /(\text { GPDDA/GOx })_{10}$ film.

bright yellow). Finally, the mixture was filtered and washed with $\mathrm{HCl}$ solution $(1: 1)$ and dried at $90{ }^{\circ} \mathrm{C}$ in vacuum.

The GPSS synthesis was performed using graphite oxide $\left(1 \mathrm{~g} \cdot \mathrm{L}^{-1}\right)$ dispersed in ultrapure water for exfoliation by sonication for $30 \mathrm{~min}$ to form graphene oxide (GO). The yellow-brown dispersion was mixed with PSS (10 mg PSS: $1 \mathrm{~mL}$ of GO dispersion) and treated with hydrazine under vigorous stirring. The mixture was kept at $90{ }^{\circ} \mathrm{C}$ for $12 \mathrm{~h}$ under reflux, filtrated and dried at $90{ }^{\circ} \mathrm{C}$ in vacuum [27]. For the GPDDA synthesis, graphite oxide $\left(0.1 \mathrm{~g} \cdot \mathrm{L}^{-1}\right)$ was dispersed in ultrapure water for exfoliation by sonication for $2 \mathrm{~h}$ to form GO, heated at $40{ }^{\circ} \mathrm{C}$ and dripped in PDDA solution $\left(30 \mathrm{~g} \cdot \mathrm{L}^{-1}\right)$ at $40^{\circ} \mathrm{C}$ under vigorous stirring. Then, hydrazine was added to the mixture $\left(0.05 \mathrm{~g} \cdot \mathrm{L}^{-1}\right)$ and kept at $90{ }^{\circ} \mathrm{C}$ for $12 \mathrm{~h}$ under reflux, filtrated and dried at room temperature in vacuum [37].

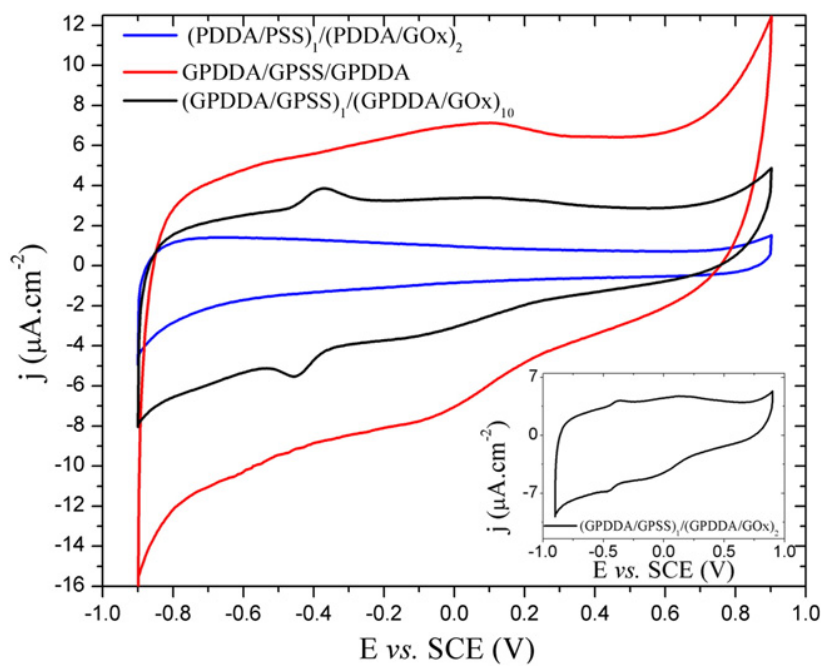

Fig. 4. Voltammograms of ITO/(GPDDA/GPSS $)_{1} /(\text { GPDDA/GOx })_{2}$ film (blue curve), ITO/ $(\text { GPDDA/GPSS })_{1} /$ GPDDA film and ITO/(GPDDA/GPSS $)_{1} /(\text { GPDDA/GOx })_{10}$. Inset: the amplified voltammogram of ITO/(GPDDA/GPSS $)_{1} /(\text { GPDDA/GOx })_{2}$. All measurements in $10 \mathrm{mmol} \cdot \mathrm{L}^{-1}, \mathrm{pH} 6.3$ and $\mathrm{N}_{2}$-saturated phosphate buffer.

\subsubsection{LbL Assembly of (GPDDA/GPSS $)_{1} /(G P D D A / G O x)_{n}$}

The gold covered glass slide was treated in a mixture of $\mathrm{NH}_{4} \mathrm{OH}$, $\mathrm{H}_{2} \mathrm{O}_{2}$ and $\mathrm{H}_{2} \mathrm{O}$, (1:1:5) for $10 \mathrm{~min}$ at $80{ }^{\circ} \mathrm{C}$, washed and dried. GPDDA and GPSS suspensions were prepared in $\mathrm{pH} 6.3$ phosphate buffer (PB). For the LbL film to grow on the substrate (gold covered glass slide for SPR analysis and ITO for electrochemical analysis), the latter was immersed in $0.1 \mathrm{mg} \cdot \mathrm{mL}^{-1}$ GPDDA dispersion for $15 \mathrm{~min}$, after which it was washed with the buffer to remove weakly adsorbed material. Then it was immersed in $0.1 \mathrm{mg} \cdot \mathrm{mL}^{-1}$ GPSS dispersion for $15 \mathrm{~min}$, followed by the same washing procedure. The film was gently dried with compressed air in each deposition step. With these procedures, the first GPDDA/GPSS bilayer was assembled. To obtain multilayers, the coated substrate was repeatedly immersed in $0.1 \mathrm{mg} \cdot \mathrm{mL}^{-1}$ GPDDA dispersion (15 min) alternated with dipping in $1 \mathrm{mg} \cdot \mathrm{mL}^{-1}$ GOx solution (10 min), with the washing and drying procedure being repeated in each deposition step. The final film architecture is substrate/(GPDDA/GPSS $)_{1} /(\text { GPDDA/GOx })_{2}$.

\section{Results and discussion}

\subsection{Characterization of GPSS and GPDDA}

The XRD patterns of graphite, GO, GPDDA and GPSS powder are shown in Fig. 1. For GO, a peak at $2 \theta=9.6^{\circ}$ is assigned to its (002) plane, thus indicating a high oxidation degree and an interlayer space (obtained by Bragg's Law equation: $\mathrm{n} \lambda=2 \mathrm{~d} \cdot \sin \theta$ ) of $0.922 \mathrm{~nm}$. This value is considerably larger than the $0.335 \mathrm{~nm}$ for graphite, which is attributed to the generation of oxygenated functional groups such as epoxy and hydroxyl groups. The GPDDA powder exhibited a broad peak at $2 \theta=23.7^{\circ}(\mathrm{d}=0.376 \mathrm{~nm})$, while a broad peak at $2 \theta=24.5^{\circ}$ $(\mathrm{d}=0.363 \mathrm{~nm}$ ) was observed for GPSS powder. The effective reduction of GO is denoted by the decrease in the interplanar distance in GPDDA and GPSS. The peak for GPDDA and GPSS is broad because it corresponds to a mixture of graphene sheets with different number of layers, which are produced as a result of different stages of functionalization of GPDDA or GPSS $[38,39]$.

The UV-VIS spectra of GO, GPDDA and GPSS aqueous dispersions are presented in Fig. S1 (see Supplementary data). For GPDDA and GPSS, in particular, a band at $270 \mathrm{~nm}$ appears due to the partial restoration of $\pi$ conjugation [38], characteristic of GO reduction. This reduction to form 


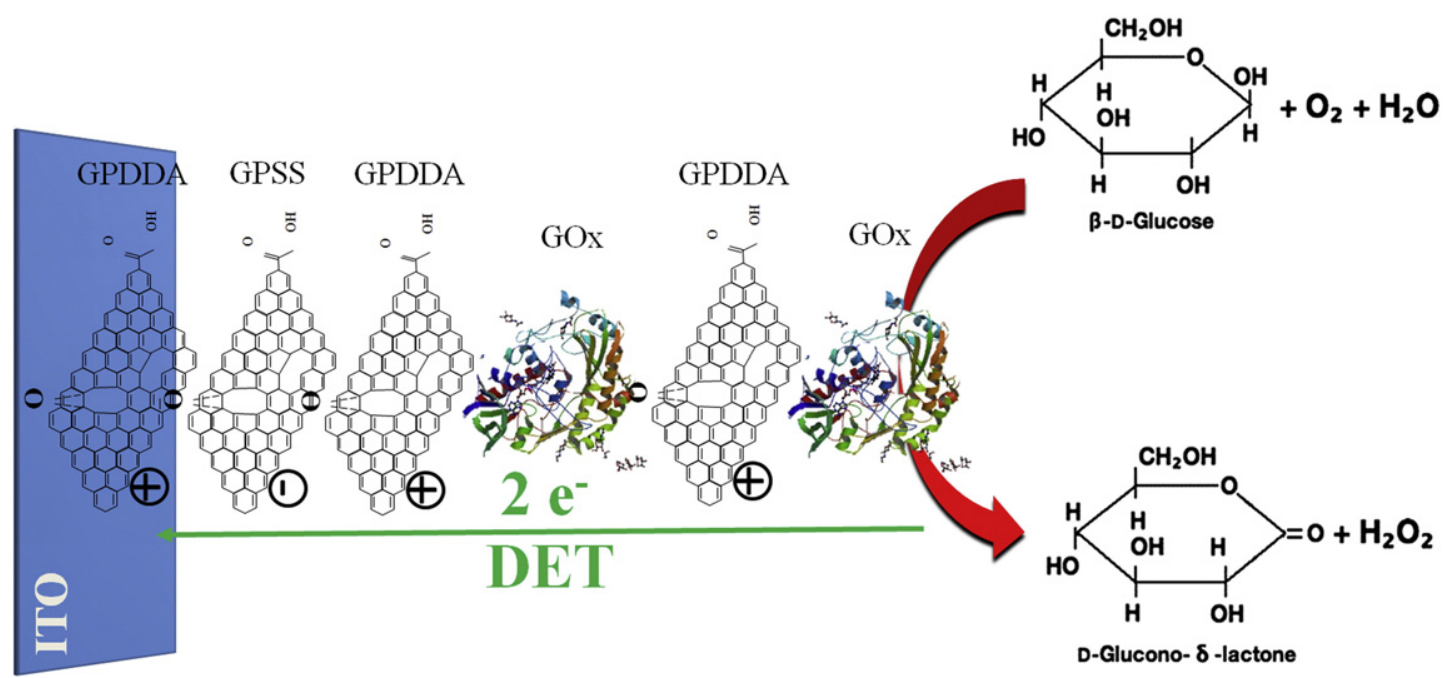

Fig. 5. Idealized scheme of an ITO electrode modified by the (GPDDA/GPSS $)_{1} /(\text { GPDDA/GOx })_{2}$ film used to detect glucose.

the intended GPDDA and GPSS was confirmed with the transmittance FTIR spectra in Fig. S2 (see Supplementary data). A clear decrease in the $1739 \mathrm{~cm}^{-1}$ band from oxide groups occurred for both GPDDA and GPSS. The functionalization of reduced GO with PDDA was confirmed by the bands in the GPDDA spectrum at $2900 \mathrm{~cm}^{-1}$ and $1476 \mathrm{~cm}^{-1}$ assigned to $\mathrm{C}-\mathrm{H}$ and $\mathrm{N}-\mathrm{C}$ stretching vibrations, respectively [38]. The characteristic bands for GPSS appear at $2900 \mathrm{~cm}^{-1}, 1175 \mathrm{~cm}^{-1}$ and $1040 \mathrm{~cm}^{-1}$ assigned to $\mathrm{C}-\mathrm{H}, \mathrm{S}-\mathrm{O}$ and S-phenyl stretching vibrations, respectively, owing to sulfonic groups. The bands at $1007 \mathrm{~cm}^{-1}$ and $830 \mathrm{~cm}^{-1}$ are assigned to in-plane $\mathrm{C}-\mathrm{H}$ bending and out of plane $\mathrm{C}-\mathrm{H}$ wagging, characteristic of $p$-disubstituted phenyl group in the effective functionalization with PSS in the nanosheets [39].

3.2. Characterization of immobilized GOx in (GPDDA/GPSS) ${ }_{1} /(G P D D A /$ GOx)n films

The growth of (GPDDA/GPSS) $1 /(\text { GPDDA/GOx })_{2}$ film was monitored by SPR, whose data are shown in Fig. 2. A shift in the minimum of

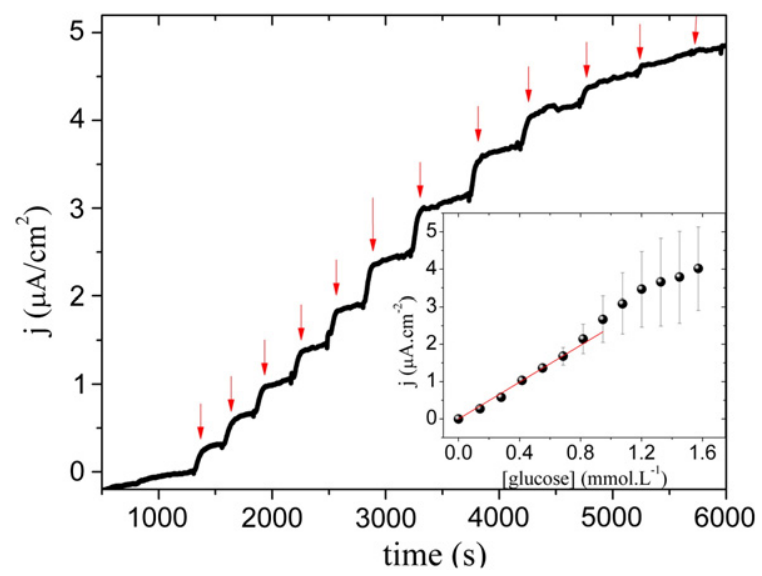

Fig. 6. Amperometric response of ITO/(GPDDA/GPSS $)_{1} /(\mathrm{GPDDA} / \mathrm{GOx})_{2}$ electrode at $-0.3 \mathrm{~V}$ vs SCE upon successive addition of $100 \mu \mathrm{L}$ of glucose in $10 \mathrm{mmol} \cdot \mathrm{L}^{-1}$ phosphate buffer ( $\mathrm{pH}$ 6.3). Inset: Analytical curve with linear range from 0.14 to $0.95 \mathrm{mmol} \cdot \mathrm{L}^{-1}$. reflection toward larger angles is due to the sequential deposition of layers. The minimum reflection angle $\theta$ was $43.029^{\circ}(\lambda=670 \mathrm{~nm})$ and $42.645^{\circ}(\lambda=785 \mathrm{~nm}$ ) for the bare substrate (no film adsorbed). The film thickness for the (GPDDA/GPSS $)_{1} /(\text { GPDDA/GOx })_{2}$ architecture was $19.80 \pm 0.28 \mathrm{~nm}$, estimated using Winspall 3.02 software based on Fresnel equations and applying the approach with two different wavelengths $[40,41]$. The simulation parameters and curve for the first GPDDA layer are presented in Fig. S3 (see Supplementary data). The thickness of the first and third GPDDA layer was $1 \mathrm{~nm}$, while the second GPDDA was approximately $2.2 \mathrm{~nm}$ thick. The thickness of each GOx layer was approximately $5 \mathrm{~nm}$, consistent with the dimensions of the native enzyme $(60 \times 52 \times 77 \AA)$ [42].

The structuring of the LbL films was analyzed with FTIR spectroscopy, and the spectra for the distinct types of film are shown in Fig. 3a. The $(\text { GPDDA/GOx })_{10}$ and (GPDDA/GPSS $)_{5} /(\mathrm{GPDDA} / \mathrm{GOx})_{5}$ films feature the $\mathrm{N}-\mathrm{H}$ stretching vibration band at $3287 \mathrm{~cm}^{-1}$ (amide A) typical of GOx. The main evidence of GOx immobilization in the (GPDDA/GOx) 10 and $(\text { GPDDA/GPSS })_{5} /(\text { GPDDA/GOx })_{5}$ films appears at $1660 \mathrm{~cm}^{-1}$, assigned to $\mathrm{C}=\mathrm{O}$ stretching vibrations of peptide linkages in the protein backbone in amide I, and at $1522 \mathrm{~cm}^{-1}$ arising from the combination of inplane $\mathrm{N}-\mathrm{H}$ bending and $\mathrm{C}-\mathrm{N}$ stretching of peptide groups. Therefore, the secondary structure of GOx was well preserved in the LbL films containing graphene nanosheets [43].

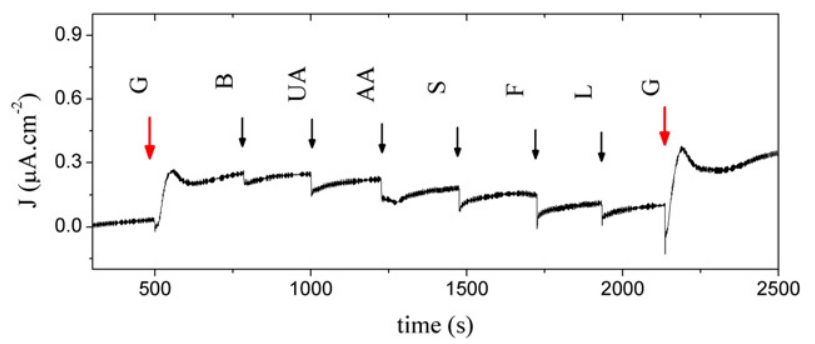

Fig. 7. Amperometric responses of ITO/(GPDDA/GPSS $)_{1} /(\text { GPDDA/GOx })_{2}$ electrode at $-0.3 \mathrm{~V}$ vs SCE upon additions of $100 \mu \mathrm{L}$ of $20 \mathrm{mmol} \cdot \mathrm{L}^{-1}$ of glucose (G), buffer (B), uric acid (UA), ascorbic acid (AA), lactose (L) sucrose (S) and fructose (F) in $10 \mathrm{mmol} \cdot \mathrm{L}^{-1}$ phosphate buffer ( $\mathrm{pH}$ 6.3). 

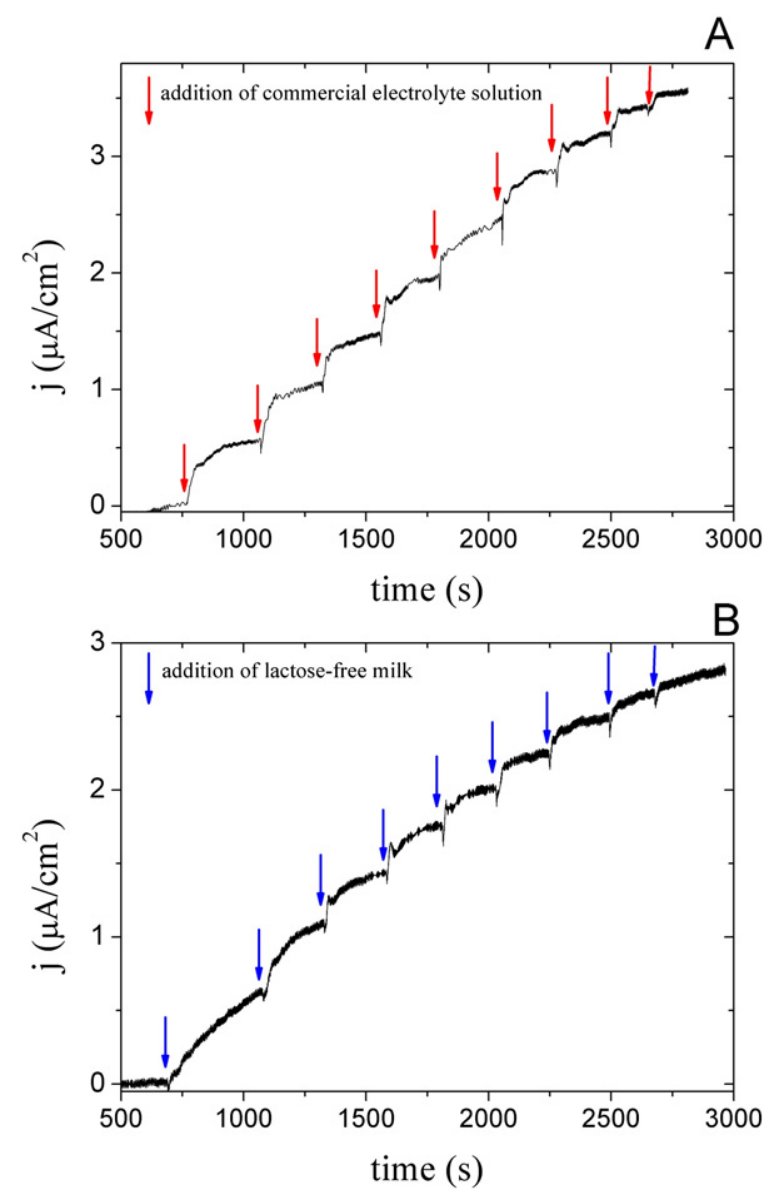

Fig. 8. Amperometric response of ITO/(GPDDA/GPSS $)_{1} /(\text { GPDDA/GOx })_{2}$ electrode at $-0.3 \mathrm{~V}$ vs SCE upon successive addition of $100 \mu \mathrm{L}$ of (a) commercial electrolyte solution (diluting factor of 10) and (b) lactose-free milk (diluting factor of 10), both in phosphate buffer ( $\mathrm{pH}$ 6.3).

The preserved structure of GOx in the LbL films was corroborated by a comparison of $\mathrm{CD}$ spectra, using free $\mathrm{GOx}$ in solution as a reference. The spectrum of free GOx in buffer solution in Fig. 3b features two minima at 218 and $208 \mathrm{~nm}$ and a maximum at $193 \mathrm{~nm}$. This spectrum is close to that of native GOx, which adopts predominantly an $\alpha$-helical structure that leads to two negative bands at 222 and $208 \mathrm{~nm}$ and a positive band at $193 \mathrm{~nm}$ [44]. For immobilized GOx in the rGO-containing LbL film the CD spectrum displays two negative bands at 220 and $210 \mathrm{~nm}$ and a positive band at $193 \mathrm{~nm}$. Therefore, GOx can be assumed to adopt predominantly an $\alpha$-helical structure, which was preserved upon deposition in the LbL film. It is worth noting that in a previous study GOx had to be encapsulated into liposomes to have its structure preserved in LbL films of polyethyleneimine (PEI) [5]. Here, rGO proved to be excellent material for GOx immobilization, with no need of
Table 2

Glucose content of commercial products.

\begin{tabular}{lll}
\hline & $\begin{array}{l}\text { Specified by the } \\
\text { manufacturer }\left(\mathrm{g} \cdot \mathrm{L}^{-1}\right)\end{array}$ & $\begin{array}{l}\text { Found with biosensor } \\
\left(\mathrm{g} \cdot \mathrm{L}^{-1}\right)\end{array}$ \\
\hline $\begin{array}{c}\text { Commercial oral } \\
\text { electrolyte solution }\end{array}$ & 25 & $25.2 \pm 0.8$ \\
Lactose-free milk & 25 & $22.2 \pm 3.4$ \\
\hline
\end{tabular}

encapsulation into liposomes, which can also be extended to other biomolecules.

The optimized potential for the amperometric detection experiments was determined from a systematic study. Indeed, optimized amperometric responses for the ITO/(GPDDA/GPSS $)_{1} /(\mathrm{GPDDA} / \mathrm{GOx})_{2}$ sensor were observed at $-0.3 \mathrm{~V}$ with successive addition of $100 \mu \mathrm{L}$ of $10 \mathrm{mmol} \cdot \mathrm{L}^{-1}$ glucose in a electrochemical cell with $7.0 \mathrm{~mL}$ of phosphate buffer pH 6.3. Fig. 6 shows that the anodic current increased fast upon addition of each glucose aliquots, owing to oxidation processes and direct conversion of $\mathrm{FADH}_{2}$ to $\mathrm{FAD}$. As shown in the inset, the increase in current is linear with glucose concentration between 0.14 and $0.95 \mathrm{mmol} \cdot \mathrm{L}^{-1}\left(\mathrm{R}^{2}=0.999\right)$. The detection limit and sensitivity were $13.4 \mu \mathrm{mol} \cdot \mathrm{L}^{-1}(\mathrm{~S} / \mathrm{N}=3)$ and $2.47 \mu \mathrm{A} \cdot \mathrm{cm}^{-2} \cdot \mathrm{mmol}^{-1} \cdot \mathrm{L}$, respectively. In subsidiary experiments we observed that the biosensing performance was inferior for the film architectures (GPDDA/GPSS) ${ }_{1} /$ $(\text { GPDDA/GOx })_{1}$ and (GPDDA/GPSS $)_{1} /(\text { GPDDA/GOx })_{5}$, which indicates there is an ideal number of layers.

Table 1 shows the analytical performance for the biosensor developed here and of similar ones from the literature. One should note that a straightforward comparison is not possible because the electrodes used to fabricate the biosensors are different. We used modified ITO electrodes, while modified glassy carbon electrodes (GCE) and gold electrodes were used in the papers mentioned in the Table. For example, the lowest detection limit [51] was obtained with a modified electrode (glassy carbon electrode, GCE), which had higher porosity and hence larger surface area for material adsorption. Nevertheless, the results given in Table 1 demonstrate that the biosensor fabricated with the LbL technique is competitive with others reported recently.

In subsidiary experiments we verified the stability of the ITO/ $(\text { GPDDA/GPSS })_{1} /(\text { GPDDA/GOx })_{2}$. When stored at $4{ }^{\circ} \mathrm{C}$, this biosensor could provide amperometric detection of glucose during 12 days. After this period, there was a decay in the anode current, which could either be caused by loss of GOx conformation or interaction between GOx and graphene (e.g., with the residual oxygen of rGO sheets, $[53,54]$ ).

\subsection{Direct electrochemistry of GOx at ITO/(GPDDA/GPSS $)_{1} /(G P D D A / G O X)_{n}$ film}

GOx is a homodimer flavoprotein obtained mainly from Aspergillus niger culture, with molecular mass between 130 and $175 \mathrm{kDa}$, isoelectric point at $\mathrm{pH} 4.2$ and optimum activity in the $\mathrm{pH}$ range between 3.5 and 6.5. It is responsible for catalyzing the oxidation reaction of $\beta$-D-glucose

Table 1

Analytical performance of ITO/(GPDDA/GPSS $)_{1} /(\mathrm{GPDDA} / \mathrm{GOx})_{2}$ biosensor and similar ones from the literature.

\begin{tabular}{|c|c|c|c|c|}
\hline Modified electrodes & Potential & Detection limit $\left(\mu \mathrm{mol} \cdot \mathrm{L}^{-1}\right)$ & Sensitivity $\left(\mu \mathrm{A} \cdot \mathrm{cm}^{-2} \cdot \mathrm{mmol}^{-1} \cdot \mathrm{L}\right)$ & Ref \\
\hline $\mathrm{AuQC} /$ chit $+(\mathrm{NG}+\mathrm{GOx}) / \mathrm{PSS}-/$ chit $+(\mathrm{NG}+\mathrm{GOx})$ & $-0.2 \mathrm{Vvs} \mathrm{Ag/AgCl}$ & 64 & 10.5 & {$[52]$} \\
\hline GCE-ATP-GNs-AuNPs-GOx & - & 9.3 and 4.1 & 47.6 & [53] \\
\hline GCE/(PEI/PAA-graphene)3(PEI/GOx)5(PEI/GA $)_{4}$ & $+0.9 \mathrm{VAg} / \mathrm{AgCl}$ & 168 & 0.261 & [28] \\
\hline GCE/(ILRGO/S-RGO)5/GOx/Nafion & $-0.2 \mathrm{Vvs} \mathrm{Ag/AgCl}$ & 3.3 & 0.00718 & {$[51]$} \\
\hline ITO/(GPDDA/GPSS $)_{1} /(\text { GPDDA-GOx })_{2}$ & $-0.3 \mathrm{~V}$ vs SCE & 13.4 & 2.47 & This work \\
\hline
\end{tabular}


into D-glucono- $\delta$-lactone and $\mathrm{H}_{2} \mathrm{O}_{2}$, using molecular oxygen as an electron acceptor. In this case, the cofactor flavin adenine dinucleotide (FAD) is reduced to $\mathrm{FADH}_{2}$, according to the reactions:

$\mathrm{GOx}(\mathrm{FAD})+\beta$-D-glucose $\rightarrow \mathrm{GOx}\left(\mathrm{FADH}_{2}\right)+\mathrm{D}$-glucono- $\delta$-lactone

$\mathrm{GOx}\left(\mathrm{FADH}_{2}\right)+\mathrm{O}_{2} \rightarrow \mathrm{GOx}(\mathrm{FAD})+\mathrm{H}_{2} \mathrm{O}_{2}$

$\mathrm{FAD}+2 \mathrm{H}^{+}+2 \mathrm{e}^{-} \leftrightarrow \mathrm{FADH}_{2}$

The mechanism suggested in Eqs. (1) and (2) for glucose detection was investigated with cyclic voltammetry, with the results being given in Fig. S4 (see Supplementary data). Fig. 4 shows redox peaks associated with the DET reaction of FAD suggested in Eq. (3). The DET characteristic well-defined peaks of the GPDDA/GPSS/(GPDDA/GOx) $)_{2}$ (19.80 thick by SPR) film were not clearly visible (curve inset Fig. 4). Thus, in order to visualize the characteristic DET peaks, a thicker film had to be used, with the architecture (GPDDA/GPSS) $)_{1}\left(\mathrm{GPDDA}_{\mathrm{GOx}}\right)_{10}$. The cathodic peak at $-0.45 \mathrm{~V}$ is assigned to the conversion of FAD to $\mathrm{FADH}_{2}$, while the anodic peak at $-0.38 \mathrm{~V}$ is ascribed to the conversion of $\mathrm{FADH}_{2}$ to FAD $[45,46]$. The well-defined redox peaks at these potentials are characteristic of DET, and the sensor can be classified as being of third generation [29]. The kind of interaction between graphene and surfactant used to functionalize rGO is important for DET, since these interactions should not generate defects in graphene sheets [47]. The functionalization in GPDDA occurs by $\pi-\pi$ interaction between graphene and PDDA [48], though electrostatic interactions with residual $-\mathrm{COO}^{-}$in graphene sheets are also possible [49]. In GPSS, functionalization occurs by $\pi-\pi$ interaction between graphene and PSS [50].

\subsubsection{Amperometric detection of glucose with ITO/(GPDDA/GPSS $)_{1} /$ (GPDDA/GOx) $)_{2}$ film}

Fig. 5 illustrates an idealized scheme for an ITO electrode modified by the (GPDDA/GPSS $)_{1}$ / (GPDDA/GOx $)_{2}$ film in detecting glucose. The charges in the nanosheets arise from the polyelectrolyte used in the functionalization of rGO.

\subsubsection{Study of interferents and stability}

Typical interfering elements in glucose detection such as uric acid (UA), ascorbic acid (AA), lactose (L), sucrose (S) and fructose (F) were tested in the amperometric experiments. Fig. 7 shows the response for the ITO / (GPDDA/GPSS $)_{1}$ / (GPDDA/GOx) $)_{2}$ sensor with interferents added to the phosphate buffer $\mathrm{pH}=6.3$. Initially, $100 \mu \mathrm{L}$ glucose at $20 \mathrm{mmol} \cdot \mathrm{L}^{-1}$ were added to generate an oxidation current. When phosphate buffer (B), UA, AA, L, S and F (100 $\mu \mathrm{L}$ and at $\left.20 \mathrm{mmol} \cdot \mathrm{L}^{-1}\right)$ were added, there was a small decrease in current, in contrast to the increased oxidation current for glucose. Therefore, glucose can be detected even if these typical interferents are present (no significant effect from them).

\subsubsection{Analysis of real samples}

Two types of real samples were evaluated with regard to their glucose content using the ITO / (GPDDA/GPSS) 1 / (GPDDA/GOx $)_{2}$ film in amperometry experiments, namely a lactose-free milk and an electrolyte solution employed against dehydration (Pedyalite $\left.{ }^{\circledR}\right)$. We highlight that the measurements were carried out without any prior treatment of the samples, unlike those commonly required in other glucose quantification methods [54]. The amperometric responses for the ITO / $(\text { GPDDA/GPSS })_{1} /$ (GPDDA/GOx $)_{2}$ sensor at $-0.3 \mathrm{~V}$ with successive addition of $100 \mu \mathrm{L}$ of real samples (diluting factor of 10 ) in an electrochemical cell with $7.0 \mathrm{~mL}$ of phosphate buffer pH 6.3 are shown in Fig. 8. Quantification of glucose in the real sample was calculated by the anodic current value of the average of the first five additions. With the commercial electrolyte solution, there is a rapid increase of anodic current due to the fast oxidation processes of glucose in the sample. The response for the lactose-free milk was slower, probably because of the difficulty in quickly diluting the colloidal milk, but it was nevertheless possible to determine the glucose content. Table 2 shows the biosensor performance, with the glucose concentration corresponding to the values specified by the manufacturers.

\section{Conclusions}

We have produced a novel bionanocomposite LbL film consisting of (GPDDA/GPSS $)_{1} /(\text { GPDDA/GOx })_{2}$, which was effective in sensing glucose. The film possesses several desirable characteristics, such as preservation of the biocatalytic activity of GOx, good stability and reproducibility. The detection limit and the sensitivity for the ITO/(GPDDA/GPSS) $)_{1} /($ GPDDA/ $\mathrm{GOx})_{2}$ glucose biosensor were $13.4 \mu \mathrm{mol} \cdot \mathrm{L}^{-1}(\mathrm{~S} / \mathrm{N}=3)$ and $2.47 \mu \mathrm{A} \cdot \mathrm{cm}^{-2} \cdot \mathrm{mmol}^{-1} \cdot \mathrm{L}$, respectively, with a linear range between 1.4 and $9.5 \mathrm{mmol} \cdot \mathrm{L}^{-1}$. Additionally, the biosensor can be employed in selective determination of glucose in the presence of interferents such as UA, AA, L, S and $\mathrm{F}$ being therefore promising for application in medicine and clinical analysis. Real samples of commercial oral electrolyte solution and lactose-free milk were successfully analyzed. The successful use of graphene nanosheets in the biosensor demonstrates that the polyelectrolytes used to functionalize graphene based on $\pi-\pi$ interactions did not affect their conductivity to any extent that would hamper application in biosensors. Therefore, LbL films with these functionalized graphene layers can now be used in other types of biosensors and bioelectrochemical devices.

\section{Acknowledgments}

The authors are grateful to FAPESP (Nos. 2014/17519-1 and 2014/ 15093-7), CNPq and CAPES (Brazil) for the financial support. The authors also thank Prof. Osvaldo N. Oliveira, Jr. for helpful discussions and Rafael Parra Ribeiro (LapTec) for help with the XRD measurements.

\section{Appendix A. Supplementary data}

Supplementary data to this article can be found online at http://dx. doi.org/10.1016/j.msec.2016.06.001.

\section{References}

[1] S. Wild, G. Roglic, A. Green, R. Sicree, H. King, Global prevalence of diabetes estimates for the year 2000 and projections for 2030, Diabetes Care 27 (2004) 1047-1053.

[2] J. Wang, Electrochemical glucose biosensors, Chem. Rev. 108 (2008) 814-825, http://dx.doi.org/10.1021/cr068123a.

[3] L.C. Clark, C. Lyons, Electrode systems for continuous monitoring in cardiovascular surgery, Ann. N. Y. Acad. Sci. 102 (1962) 29-45, http://dx.doi.org/10.1111/j.17496632.1962.tb13623.x.

[4] G. Decher, J.B. Schlenoff, Multilayer Thin Films: Sequential Assembly of Nanocomposite Materials, John Wiley \& Sons, 2012.

[5] J.S. Graça, R.F. de Oliveira, M.L. de Moraes, M. Ferreira, Amperometric glucose biosensor based on layer-by-layer films of microperoxidase-11 and liposome-encapsulated glucose oxidase, Bioelectrochemistry 96 (2014) 37-42, http://dx.doi.org/10. 1016/j.bioelechem.2014.01.001.

[6] J.-A. He, R. Valluzzi, K. Yang, T. Dolukhanyan, C. Sung, J. Kumar, S.K. Tripathy, L. Samuelson, L. Balogh, D.A. Tomalia, Electrostatic multilayer deposition of a golddendrimer nanocomposite, Chem. Mater. 11 (1999) 3268-3274, http://dx.doi.org/ 10.1021/cm990311c.

[7] D.T. Haynie, S. Balkundi, N. Palath, K. Chakravarthula, K. Dave, Polypeptide multilayer films: role of molecular structure and charge, Langmuir 20 (2004) 4540-4547, http://dx.doi.org/10.1021/la036330p.

[8] B. Munge, G. Liu, G. Collins, J. Wang, Multiple enzyme layers on carbon nanotubes for electrochemical detection down to 80 DNA copies, Anal. Chem. 77 (2005) 4662-4666, http://dx.doi.org/10.1021/ac050132g.

[9] P. He, N. Hu, Electrocatalytic properties of heme proteins in layer-by-layer films assembled with SiO2 nanoparticles, Electroanalysis 16 (2004) 1122-1131, http://dx. doi.org/10.1002/elan.200403000.

[10] P.J. Yoo, K.T. Nam, J. Qi, S.-K. Lee, J. Park, A.M. Belcher, P.T. Hammond, Spontaneous assembly of viruses on multilayered polymer surfaces, Nat. Mater. 5 (2006) 234-240, http://dx.doi.org/10.1038/nmat1596.

[11] D. Wakizaka, T. Fushimi, H. Ohkita, S. Ito, Hole transport in conducting ultrathin films of PEDOT/PSS prepared by layer-by-layer deposition technique, Polymer 45 (2004) 8561-8565, http://dx.doi.org/10.1016/j.polymer.2004.10.007. 
[12] Y.-C. Li, J. Schulz, S. Mannen, C. Delhom, B. Condon, S. Chang, M. Zammarano, J.C. Grunlan, Flame retardant behavior of polyelectrolyte-clay thin film assemblies on cotton fabric, ACS Nano 4 (2010) 3325-3337, http://dx.doi.org/10.1021/ nn100467e.

[13] Z. Poon, D. Chang, X. Zhao, P.T. Hammond, Layer-by-layer nanoparticles with a pHsheddable layer for in vivo targeting of tumor hypoxia, ACS Nano 5 (2011) 4284-4292, http://dx.doi.org/10.1021/nn200876f.

[14] P.R. Dalmasso, M.L. Pedano, G.A. Rivas, Supramolecular architecture based on the self-assembling of multiwall carbon nanotubes dispersed in polyhistidine and glucose oxidase: characterization and analytical applications for glucose biosensing, Biosens. Bioelectron. 39 (2013) 76-81, http://dx.doi.org/10.1016/j.bios.2012.06. 041.

[15] S. Liu, J. Yan, G. He, D. Zhong, J. Chen, L. Shi, X. Zhou, H. Jiang, Layer-by-layer assembled multilayer films of reduced graphene oxide/gold nanoparticles for the electrochemical detection of dopamine, J. Electroanal. Chem. 672 (2012) 40-44, http://dx doi.org/10.1016/j.jelechem.2012.03.007.

[16] M. Ferreira, P.A. Fiorito, O.N. Oliveira, S.I. Córdoba de Torresi, Enzyme-mediated amperometric biosensors prepared with the layer-by-layer (LbL) adsorption technique, Biosens. Bioelectron. 19 (2004) 1611-1615, http://dx.doi.org/10.1016/j.bios.2003. 12.025 .

[17] M.N. Karim, J.E. Lee, H.J. Lee, Amperometric detection of catechol using tyrosinase modified electrodes enhanced by the layer-by-layer assembly of gold nanocubes and polyelectrolytes, Biosens. Bioelectron. 61 (2014) 147-151, http://dx.doi.org/ 10.1016/j.bios.2014.05.011.

[18] W. Nouira, H. Barhoumi, A. Maaref, N.J. Renault, M. Siadat, Tailoring of analytical performances of urea biosensors using nanomaterials, J. Phys. Conf. Ser. 416 (2013) 12010, http://dx.doi.org/10.1088/1742-6596/416/1/012010.

[19] K. Ariga, Q. Ji, J.P. Hill, Y. Bando, M. Aono, Forming nanomaterials as layered functional structures toward materials nanoarchitectonics, NPG Asia Mater. 4 (2012) e17, http://dx.doi.org/10.1038/am.2012.30.

[20] J.R. Siqueira, L. Caseli, F.N. Crespilho, V. Zucolotto, O.N. Oliveira, Immobilization of biomolecules on nanostructured films for biosensing, Biosens. Bioelectron. 25 (2010) 1254-1263, http://dx.doi.org/10.1016/j.bios.2009.09.043.

[21] A.K. Geim, K.S. Novoselov, The rise of graphene, Nat. Mater. 6 (2007) 183-191, http://dx.doi.org/10.1038/nmat1849.

[22] S. Basu, P. Bhattacharyya, Recent developments on graphene and graphene oxide based solid state gas sensors, Sensors Actuators B Chem. 173 (2012) 1-21, http:// dx.doi.org/10.1016/j.snb.2012.07.092.

[23] L. Ding, Y. Liu, S.-X. Guo, J. Zhai, A.M. Bond, J. Zhang, Phosphomolybdate@ poly(diallyldimethylammonium chloride)-reduced graphene oxide modified electrode for highly efficient electrocatalytic reduction of bromate, J. Electroanal Chem. 727 (2014) 69-77, http://dx.doi.org/10.1016/j.jelechem.2014.06.001.

[24] O. Akhavan, E. Ghaderi, R. Rahighi, Toward single-DNA electrochemical biosensing by graphene nanowalls, ACS Nano 6 (2012) 2904-2916, http://dx.doi.org/10 1021/nn300261t

[25] O. Akhavan, E. Ghaderi, R. Rahighi, M. Abdolahad, Spongy graphene electrode in electrochemical detection of leukemia at single-cell levels, Carbon 79 (2014) 654-663, http://dx.doi.org/10.1016/j.carbon.2014.08.058.

[26] O. Akhavan, E. Ghaderi, E. Hashemi, R. Rahighi, Ultra-sensitive detection of leukemia by graphene, Nanoscale 6 (2014) 14810-14819, http://dx.doi.org/10.1039/ C4NR04589K.

[27] S. Stankovich, R.D. Piner, X. Chen, N. Wu, S.B.T. Nguyen, R.S. Ruoff, Stable aqueous dispersions of graphitic nanoplatelets via the reduction of exfoliated graphite oxide in the presence of poly (sodium 4-styrenesulfonate), J. Mater. Chem. 16 (2006) 155-158

[28] G. Zeng, Y. Xing, J. Gao, Z. Wang, X. Zhang, Unconventional layer-by-layer assembly of graphene multilayer films for enzyme-based glucose and maltose biosensing Langmuir 26 (2010) 15022-15026, http://dx.doi.org/10.1021/la102806v.

[29] L. Gorton, A. Lindgren, T. Larsson, F.D. Munteanu, T. Ruzgas, I. Gazaryan, Direct electron transfer between heme-containing enzymes and electrodes as basis for third generation biosensors, Anal. Chim. Acta 400 (1999) 91-108.

[30] V. Mani, B. Devadas, S.-M. Chen, Direct electrochemistry of glucose oxidase at electrochemically reduced graphene oxide-multiwalled carbon nanotubes hybrid material modified electrode for glucose biosensor, Biosens. Bioelectron. 41 (2013) 309-315, http://dx.doi.org/10.1016/j.bios.2012.08.045.

[31] S. Palanisamy, C. Karuppiah, S.-M. Chen, Direct electrochemistry and electrocatalysis of glucose oxidase immobilized on reduced graphene oxide and silver nanoparticles nanocomposite modified electrode, Colloids Surf. B Biointerfaces 114 (2014) 164-169, http://dx.doi.org/10.1016/j.colsurfb.2013.10.006.

[32] S. Palanisamy, S. Cheemalapati, S.-M. Chen, Amperometric glucose biosensor based on glucose oxidase dispersed in multiwalled carbon nanotubes/graphene oxide hybrid biocomposite, Mater. Sci. Eng. C 34 (2014) 207-213, http://dx.doi.org/10.1016/ j.msec.2013.09.011.
[33] X. Kang, J. Wang, H. Wu, I.A. Aksay, J. Liu, Y. Lin, Glucose oxidase-graphene-chitosan modified electrode for direct electrochemistry and glucose sensing, Biosens. Bioelectron. 25 (2009) 901-905, http://dx.doi.org/10.1016/j.bios.2009.09.004.

[34] P. Wu, Q. Shao, Y. Hu, J. Jin, Y. Yin, H. Zhang, C. Cai, Direct electrochemistry of glucose oxidase assembled on graphene and application to glucose detection, Electrochim. Acta 55 (2010) 8606-8614, http://dx.doi.org/10.1016/j.electacta.2010.07.079.

[35] N.I. Kovtyukhova, P.J. Ollivier, B.R. Martin, T.E. Mallouk, S.A. Chizhik, E.V. Buzaneva, A.D. Gorchinskiy, Layer-by-layer assembly of ultrathin composite films from micron-sized graphite oxide sheets and polycations, Chem. Mater. 11 (1999) 771-778, http://dx.doi.org/10.1021/cm981085u.

[36] W.S. Hummers Jr., R.E. Offeman, Preparation of graphitic oxide, J. Am. Chem. Soc. 80 (1958) 1339.

[37] Y. Li, C. Deng, M. Yang, Facilely prepared composites of polyelectrolytes and graphene as the sensing materials for the detection of very low humidity, Sensors Actuators B Chem. 194 (2014) 51-58, http://dx.doi.org/10.1016/j.snb.2013.12.080.

[38] D. Peng, J. Zhang, D. Qin, J. Chen, D. Shan, X. Lu, An electrochemical sensor based on polyelectrolyte-functionalized graphene for detection of 4-nitrophenol, J. Electroanal. Chem. 734 (2014) 1-6, http://dx.doi.org/10.1016/j.jelechem.2014.09. 027.

[39] Y. Si, E.T. Samulski, Synthesis of water soluble graphene, Nano Lett. 8 (2008) 1679-1682, http://dx.doi.org/10.1021/nl080604h.

[40] N. Granqvist, H. Liang T. Laurila, J. Sadowski, M. Yliperttula, T. Viitala, Characterizing ultrathin and thick organic layers by Surface Plasmon Resonance three-wavelength and waveguide mode analysis, Langmuir 29 (2013) 8561-8571, http://dx.doi.org/ 10.1021/la401084w.

[41] H. Liang, H. Miranto, N. Granqvist, J.W. Sadowski, T. Viitala, B. Wang, M. Yliperttula, Surface plasmon resonance instrument as a refractometer for liquids and ultrathin films, Sensors Actuators B Chem. 149 (2010) 212-220, http://dx.doi.org/10.1016/ j.snb.2010.05.048.

[42] H.C. Yoon, H.-S. Kim, Multilayered assembly of dendrimers with enzymes on gold: thickness-controlled biosensing interface, Anal. Chem. 72 (2000) 922-926, http:// dx.doi.org/10.1021/ac991299a.

[43] W. Liang, Y. Zhuobin, Direct electrochemistry of glucose oxidase at a gold electrode modified with single-wall carbon nanotubes, Sensors 3 (2003) 544-554.

[44] E. Tellechea, K.J. Wilson, E. Bravo, K. Hamad-Schifferli, Engineering the interface between glucose oxidase and nanoparticles, Langmuir 28 (2012) 5190-5200, http:// dx.doi.org/10.1021/la2050866.

[45] K.-Y. Hwa, B. Subramani, Synthesis of zinc oxide nanoparticles on graphene-carbon nanotube hybrid for glucose biosensor applications, Biosens. Bioelectron. 62 (2014) 127-133, http://dx.doi.org/10.1016/j.bios.2014.06.023.

[46] Y.-F. Bai, T.-B. Xu, J.H.T. Luong, H.-F. Cui, Direct electron transfer of glucose oxidaseboron doped diamond Interface: a new solution for a classical problem, Anal. Chem. 86 (2014) 4910-4918, http://dx.doi.org/10.1021/ac501143e.

[47] D. Parviz, S. Das, H.S.T. Ahmed, F. Irin, S. Bhattacharia, M.J. Green, Dispersions of noncovalently functionalized graphene with minimal stabilizer, ACS Nano 6 (2012) 8857-8867, http://dx.doi.org/10.1021/nn302784m.

[48] D.-O. Yang, J.-F. Rochette, E. Sacher, Spectroscopic evidence for $\pi-\pi$ interaction between poly (diallyl dimethylammonium) chloride and multiwalled carbon nanotubes, J. Phys. Chem. B 109 (2005) 4481-4484

[49] J.H. Rouse, P.T. Lillehei, Electrostatic assembly of polymer/single walled carbon nanotube multilayer films, Nano Lett. 3 (2003) 59-62, http://dx.doi.org/10.1021/ nl025780j.

[50] F.-P. Du, J.-J. Wang, C.-Y. Tang, C.-P. Tsui, X.-P. Zhou, X.-L. Xie, Y.-G. Liao, Water-soluble graphene grafted by poly(sodium 4-styrenesulfonate) for enhancement of electric capacitance, Nanotechnology 23 (2012) 475704, http://dx.doi.org/10. 1088/0957-4484/23/47/475704.

[51] H. Gu, Y, Yu, X. Liu, B. Ni, T. Zhou, G. Shi, Layer-by-layer self-assembly of functionalized graphene nanoplates for glucose sensing in vivo integrated with on-line microdialysis system, Biosens. Bioelectron. 32 (2012) 118-126, http://dx.doi.org/10. 1016/j.bios.2011.11.044.

[52] M.M. Barsan, M. David, M. Florescu, L. Tugulea, C.M.A. Brett, A new self-assembled layer-by-layer glucose biosensor based on chitosan biopolymer entrapped enzyme with nitrogen doped graphene, Bioelectrochemistry 99 (2014) 46-52, http://dx. doi.org/10.1016/j.bioelechem.2014.06.004.

[53] R.K. Shervedani, A. Amini, Novel graphene-gold hybrid nanostructures constructed via sulfur modified graphene: preparation and characterization by surface and electrochemical techniques, Electrochimica Acta. 121 (2014) 376-385, http://dx.doi. org 1 10.1016/j.electacta.2013.12.044.

[54] L.D. Mello, L.T. Kubota, Review of the use of biosensors as analytical tools in the food and drink industries, Food Chem. 77 (2002) 237-256 